\title{
Modelling the Asymmetric Volatility in Hog Prices in Taiwan: The Impact of Joining the WTO
}

\author{
Chia-Lin Chang ${ }^{*}$ \\ Department of Applied Economics \\ National Chung Hsing University \\ Biing-Wen Huang \\ Department of Applied Economics \\ National Chung Hsing University \\ Meng-Gu Chen \\ Department of Applied Economics \\ National Chung Hsing University \\ Michael McAleer \\ Department of Quantitative Economics \\ Complutense University of Madrid
}

Revised: March 2009

\footnotetext{
* Corresponding author: Chia-Lin Chang, Department of Applied Economics National Chung Hsing University Taichung, 250 Kuo Kuang Road, National Chung Hsing University Taichung 402, Taiwan, changchialin@nchu.edu.tw, Tel: +886 (04)22840350 ext 309. Fax: +886(04)22860255.
} 


\begin{abstract}
The hog industry, where prices are determined according to an auction system, is of vital importance to the agricultural industry in Taiwan by providing significant production and employment. In particular, there were significant impacts on daily hog prices in the periods before, during and after joining the WTO, which we will refer to as periods of anticipation, adjustment and settlement. The purpose of the paper is to model the growth rates and volatility in daily hog prices in Taiwan from 23 March 1999 to 30 June 2007, which enables an analysis of the effects of joining the WTO. The paper provides a novel application of financial volatility models to agricultural finance. The empirical results have significant implications for risk management and policy considerations in the agricultural industry in Taiwan, especially when significant structural changes, such as joining the WTO, are concerned. The three sub-samples relating to the period before, during and after joining the WTO display significantly different volatility persistence, namely symmetry, asymmetry but not leverage, and leverage, respectively, whereby negative shocks increase volatility but positive shocks of a similar magnitude decrease volatility.
\end{abstract}

Keywords and phrases: Hog prices, joining the WTO, conditional volatility models, asymmetry, leverage, moment conditions.

JEL Classifications: Q14, G18,G32 


\section{Introduction}

Time-varying volatility in agricultural commodity prices, such as hog prices, usually accompanies riskiness in the rates of growth (or returns). How to capture the pattern or characteristics of volatility is of concern to farmers. Under the World Trade Organization (WTO) regulations, direct price support programs of agricultural authorities have had to be progressively eliminated, so that farm prices are essentially determined by the market. Therefore, the volatility associated with prices imposes significant pressures on agricultural producers.

Price changes are associated with volatility and risk. If agricultural commodity prices have predictable time-varying volatility, they can be analysed using recently developed financial econometric methods that incorporate important aspects of optimal portfolio management. McAleer (2008) explains why time-varying volatility can be useful in areas such as environmental finance and tourism finance. Similar arguments can be used for applications in agricultural finance. Volatility from high frequency data can be aggregated, whereas aggregated data at low frequencies typically display no volatility, thereby enabling the prediction of risk associated with the imposition of agricultural taxes. Dynamic confidence intervals can also be computed. Moreover, modelling volatility permits an analysis of the asymmetric and leveraged responses of prices and associated commodity inflation rates to positive and negative shocks of equal magnitude. In this way, commodity prices behave like financial stock prices, so that the theory of finance can be applied directly to agricultural commodity prices.

In order to assist farmers to predict the volatility in prices, several related issues need to be investigated. This paper focuses on the asymmetric response of volatility to positive and negative shocks to prices and returns because the stochastic property of agricultural commodity prices might not be symmetric. The empirical models examined in this paper will evaluate hog prices, their returns and associated volatility in Taiwan. 
The hog industry is the biggest industry in the livestock sector in Taiwan. According to the Agricultural Statistics Yearbook in Taiwan, the quantity of production was 930,609 tons in 2006, and its value amounted to NT\$ 55.5 billion, which is $14.72 \%$ of total agricultural production. There were 12,508 hog farms in 2006 and there were around 7 million hogs on farms at the end of the year. Furthermore, the feed industry is closely related to the hog industry as $45.5 \%$ of feed products, namely 7.7 million tons, were provided for hog production in 2006. The raw material for feed comes from grain imports. For example, the imported quantity of corn was around 5 million tons in 2006, with the main source of imports being the USA. Thus, the hog industry not only plays an important role in Taiwan's agricultural sector, but it is also closely related to the grain exports country.

With regard to the development of the hog industry in Taiwan, farmers typically raised hogs as a secondary source of income prior to the 1960s, where the number of hogs at the end of the year was around 3 million heads. Since production technology has gradually improved over time and agricultural authorities encouraged farmers to raise hogs, the hog industry became more commercialized in the 1970s and thereafter developed quickly. The total number of hogs increased from 2.9 million heads to 4.8 million heads, but the number of hog farms decreased from 583,127 to 175,178 during the period 1970-1980. In the 1980s, the industry prospered, exports expanded rapidly, and the total number of hogs at the end of the year increased to historical higher levels of around 10 million heads in 1990.

Until the mid-1990s, the hog industry was still developing steadily and exports were increasing, with a peak of around US\$ 1.5 billion being reached in 1996. The industry was also the largest exporter of agricultural commodities. Unfortunately, in 1997 the outbreak of foot and mouth disease caused significant damage to this industry and resulted in restriction of exports. The total number of hogs at the end of the year decreased to 8 million heads in 1997, and the value of hog production decreased dramatically from NT\$ 88.6 billion to NTS 44.7 billion in 1996-97. Subsequently, the 
production of hogs has adjusted to concentrate on the domestic market from the late 1990s to the present.

After Taiwan applied to join the WTO in the 1990s, import restrictions on pork, except for pork bellies and some offal, were gradually deregulated for purposes of meeting trade liberalization requirements. Pork imports are primarily from the USA and the quantity imported annually fluctuates significantly, such as 19,507 tons in 2002, 40,150 tons in 2004, and 18,546 tons in 2006, depending on market factors. After Taiwan joined the WTO in 2002, pork bellies and some offal were deregulated, based on the quota system during 2002-2004, and free imports were permitted from 2005. In order to confront the serious situation, particularly in the planning stages of Taiwan's joining the WTO, the government encouraged inefficient farmers to move away from hog production by providing subsidies. Consequently, the total number of hog farms decreased from 20,454 to 13054 during 1997-2002. However, the average raising scale was enlarged from 390 to 520 heads during the same period, and was then increased to 565 heads in 2006. This implies that the competitiveness of the hog industry in Taiwan was strengthened during the period that Taiwan was applying to join the WTO.

The hog farm price is determined by an auction system in the local wholesale markets. There are 23 local hog wholesale markets in Taiwan. Farmers may transport their hogs to any markets according to the price in each market, which is accordingly very similar to a perfectly competitive market. As the consumption of pork in Taiwan has not changed markedly over time, having stabilized at around $40 \mathrm{~kg}$ per capita per year over the last decade, this indicates that the demand side for hogs is relatively steady. Therefore, hog farm prices are primarily affected by domestic supply and by hog imports. The liberalization of pork imports has complicated the analysis of the factors that determine hog farm prices. Hog farm prices have displayed significant fluctuations, varying from NT\$ 62.46 per $\mathrm{kg}$ in 1999 to NT\$ 40.13 per $\mathrm{kg}$ in 2001, and then to NT\$ 59.60 per $\mathrm{kg}$ in 2004 . The volatility of hog farm prices is of serious concern to farmers because it is directly related to returns and their associated risk. 
Despite farmers taking notice of the volatility in daily hog prices, the agricultural authorities in Taiwan also pay strong attention to hog farm price information. In order to assist farmers to overcome the impacts of imported livestock products, the agricultural authorities established the National Animal Industry Foundation (NAIF) in 2000. One of the main tasks of the NAIF is to evaluate hog price information as the basis for strategic guidance and operational assistance.

When the price is higher than the historical average, the NAIF will announce an early warning to urge farmers not to raise too many pigs. On the other hand, when the price is considerably lower than the historical average, the NAIF will provide some indirect support programs to raise prices to an acceptable level. For example, the NAIF might provide subsidies for framers to encourage them to stop raising pigs temporarily, or for processing plants to stock pork in warehouses. Such measures will reduce the supply of pork, so that hog farm prices would be expected to recover. Consequently, the volatility in hog farm prices would be affected. Importantly, the volatility in such prices might be expected to be time-varying, in which case they can be modelled and predicted using financial econometric methods.

With regard to the volatility in the prices of agricultural commodities, Langley et al. (2000) analyzed the relationship between international financial volatility in 1997 and agricultural commodity trade in Thailand. The GARCH(1,1) conditional volatility model was used to estimate the variance of the exchange rate as a measure of financial risk (or volatility), and it was found that there were strong impacts of exchange rate risk on poultry, though not on aggregate, exports. Lence and Hayes (2002) examined the significant volatility in U.S. corn, soybean and wheat prices during 1995-2000 and its connection to the Federal Agricultural Improvement and Reform (FAIR) Act of 1996. A dynamic three-commodity rational expectations storage model was used to simulate the scenarios of the pre-FAIR and FAIR regimes, and it was determined empirically that the grain price volatility was not due to FAIR. Shively (2001) investigated the price threshold and volatility in an African maize market. The results from the ARCH and threshold 
ARCH conditional volatility models suggested that the price volatility was subject to a threshold, such that larger price increases produced greater subsequent volatility.

Other research has concentrated on the volatility in agricultural futures prices. Jin and Frechette (2004) analysed the presence of fractional integration to explain the volatility of U.S. agricultural futures prices, and showed that the $\operatorname{FIGARCH}(1, \mathrm{~d}, 1)$ fractional integration model was superior empirically to GARCH $(1,1)$. Koekebakker and Lien (2004) analyzed the U.S. wheat futures prices for time-varying volatility with a jump diffusion process, and found that the price volatility of wheat options was affected differentially by seasonal, maturity and jump effects. Egelkraut et al. (2007) examined the term structure of volatility and showed that the implied forward volatility was successful in explaining the realized volatility in the corn options market.

ARCH and GARCH conditional volatility models have been applied widely to accommodate the time-varying heteroskedasticity that is associated with the riskiness in price movements in the hog market. For example, Chang (1999) applied the ARCH model using monthly data in Taiwan to examine changes in hog farm prices. The empirical results showed that hog farm prices displayed time-varying conditional heteroskedasticity, which implies that hog farmers face price volatility during the production process. Lien and Hennessy (2007) used the AR (1)-GARCH(1,1) model with weekly data for Saskatchewan, Canada, to estimate the hog spot price stochastic process and generate simulated prices. These prices were used to evaluate whether farmers received benefits from the short run hog loan program of 2002.

Schroeter and Azzam (1991) analyzed the effects of U.S pork price uncertainty on farm wholesale margins. The ARCH(2) model was used to estimate the conditional forecast variance, and the results indicated that the output price risk component significantly affected the marketing margins. Yang and Brorsen (1992) tested daily cash prices with daily data for nine commodities, including pork bellies, for normality and nonlinear independence. Their conclusions showed that the GARCH model was superior 
to the alternative considered, thereby forming the basis for theoretical and applied work in agricultural finance.

To date, any discussions in the agricultural finance literature regarding the short and long run persistence of shocks, and the possibly asymmetric effects of positive and negative shocks of similar magnitude on the volatility in agricultural prices, has been scarce. This suggests that the issue of asymmetric volatility remains relatively unexplored. If hog farmers and the hog industry could understand the information content in models of hog prices, growth rates and their associated volatility, they could undertake profitable and optimal risk management strategies.

The purpose of the paper is to model the prices, growth rates and their respective volatilities in daily hog prices in Taiwan from 23 March 1999 to 30 June 2007. A novel application of financial volatility models to agricultural finance is given, which should be relevant for the analysis of other agricultural commodities in different countries. The empirical results show that the time series of hog prices and their logarithms are nonstationary, but that their log differences (or growth rates) are stationary. In addition, the estimated symmetric and asymmetric conditional volatility models, specifically the GARCH, GJR and EGARCH models, all fit the data extremely well. The empirical second moment and log-moment conditions also support the statistical adequacy of both the estimated symmetric and asymmetric conditional volatility models.

The remainder of the paper is organized as follows. Section 2 presents the data for daily hog prices in Taiwan, performs a test of structural change across three regimes associated with the planning, adjustment and settlement stages of joining the WTO, and discusses the time-varying volatility. Section 3 performs unit root tests on the levels, logarithms and growth rates of daily hog prices. Section 4 discusses alternative conditional mean and conditional volatility models for daily hog prices. The estimated models and empirical results are discussed in Section 5. Finally, some concluding remarks are given in Section 6. 


\section{Data}

The data set comprises daily hog prices in Taiwan from 23 March 1999 to 30 June 2007, giving a total of 2,024 observations. The data were obtained from the website of the National Animal Industry Foundation (NAIF) in Taiwan.

Figures 1-3 plot the trends in daily hog prices (Y), the logarithm of daily hog prices (LY), and the first difference (that is, the log difference or growth rate) of daily hog prices (DLY), as well as the volatility of the three variables, where volatility is defined as the squared deviation from the sample mean.

As shown in Figures 1 and 2, there has been a large decrease in daily hog prices, as well as in the logarithm of daily hog prices, during the period 23 June 1999 to 27 December 2001, a large increase in prices and log prices during the period 28 December 2001 to 6 August 2004, and then a significant reduction in prices and log prices during the period 7 August 2004 to 30 June 2007.

Furthermore, the series in levels and logarithms might be stationary or nonstationary, but the log difference series is clearly stationary. As shown in Figure 3, there is clear volatility persistence in daily hog prices for the log difference series. However, hog prices display volatility that would seem to be different in various sub-sample periods. In particular, there would seem to be greater volatility in hog prices for subsample 2 for 2001 to 2004 as compared with sub-sample 1 for 1999 to 2001 and subsample 3 for 2004 to 2007.

As described above, there would seem to be significant increasing and decreasing trends in the daily hog price and logarithmic hog price throughout the sample period. These variations in daily hog prices are likely to have been caused by Taiwan's decision to join the World Trade Organization (WTO) in 2002, whereby trade liberalization led to strikes in the domestic hog market in Taiwan. Prominently, the three sub-samples described above correspond to the three stages in terms of Taiwan joining the WTO. For 
this reason, we will interpret sub-sample 1 as the "planning" stage of Taiwan joining the WTO, sub-sample 2 as the "adjustment" period immediately after Taiwan joined the WTO, and sub-sample 3 as the "settlement" stage.

Table 1 presents the results of the Chow breakpoint tests of the null hypothesis of no structural change across the three regimes, namely 1999/3/23-2001/12/27, $2001 / 12 / 28-2004 / 8 / 6$ and 2004/8/7-2007/6/30. As the timing of the structural change is presumed to be known, it is not necessary to estimate the dates of the breakpoints (for further details, see Bai and Perron $(1998,2003))$. Both the F and likelihood ratio tests reject the null hypothesis at the 5\% level of significance, which lends support to the view that joining the WTO led to structural change.

In the next section, we analyze the presence of a stochastic trend by applying unit root tests before modelling the time-varying volatility that would seem to be present in the levels, logarithms and log differences (or growth rates) in the respective series.

\section{Unit Root Tests}

It is well known that traditional unit root tests, primarily those based on the classic methods of Dickey and Fuller (1979, 1981) and Phillips and Perron (1988), suffer from low power and size distortions. However, these shortcomings have been overcome by modifications to the testing procedures, such as the methods proposed by Perron and Ng (1996), Elliott, Rothenberg and Stock (1996), and Ng and Perron (2001).

The modified unit root tests given by $\mathrm{MADF}^{\mathrm{GLS}}$ and MPP $\mathrm{MLS}^{\mathrm{GLS}}$ were applied to the time series of daily hog prices in Taiwan. In essence, these tests use GLS de-trended data and the modified Akaike information criterion (MAIC) to select the optimal truncation lag. The asymptotic critical values for both tests are given in Ng and Perron (2001).

The results of the unit root tests are obtained from the econometric software package EViews 5.0, and are reported in Tables 2a-2d. Table 1 shows the results of unit 
root tests for the full sample period, while Tables $2 b-2 d$ show the results for each of the three sub-sample periods, respectively. As shown in Table 1, the null hypothesis of a unit root is not rejected for the levels of daily hog prices in the models with a constant and with a constant and trend as the deterministic terms. A similar result holds for the logarithms of daily hog prices, where both the $\mathrm{MADF}^{\mathrm{GLS}}$ and MPP ${ }^{\mathrm{GLS}}$ tests do not reject the null hypothesis of a unit root for the models with a constant and with a constant and trend. However, for the series in log differences (or growth rates), the null hypothesis of a unit root is rejected for both specifications using both the MADF ${ }^{\mathrm{GLS}}$ and MPP ${ }^{\mathrm{GLS}}$ tests.

Overall, the null hypothesis of a unit root is not rejected for the levels or logarithms of daily hog prices, but is rejected for the growth rate of daily hog prices. Similar results of the unit root tests are found in each of the three sub-samples.

As shown in the unit root tests, the empirical results strongly suggest the use of growth rates in daily hog prices in Taiwan to estimate alternative univariate conditional mean and conditional volatility models simultaneously. For this reason, conditional mean and conditional volatility models will be estimated in Section 5 using only the growth rate of daily hog prices in Taiwan for various sub-samples of the data.

\section{Conditional Mean and Conditional Volatility Models}

The alternative time series models to be estimated for the conditional means of the daily hog prices, as well as their respective conditional volatilities, are discussed below. As Figures 1-3 illustrate, daily hog prices and the logarithm of daily hog prices do not show persistence in volatility, whereas the first differences (that is, the log difference or growth rate) of daily hog prices in Taiwan show periods of persistent high volatility from 23 June 1999 to 27 December 2001, followed by relatively low volatility from 23 June 1999 to 27 December 2001, and then by relatively high volatility from 28 December 2001 to 6 August 2004. One implication of this persistent time-varying volatility is that the assumption of conditionally homoskedastic residuals would seem to be inappropriate for sensible empirical analysis. 
For a wide range of financial data series, time-varying conditional variances can be explained empirically through the autoregressive conditional heteroskedasticity (ARCH) model of Engle (1982). When the time-varying conditional variance has both autoregressive and moving average components, this leads to the generalized $\operatorname{ARCH}(p, q)$, or $\operatorname{GARCH}(p, q)$, model of Bollerslev (1986). The lag structure of the appropriate GARCH model can be chosen by information criteria, such as those of Akaike and Schwarz, although it is very common to impose the widely estimated GARCH(1,1) specification in advance.

In the selected conditional volatility model, the residual series should follow a white noise process. Bollerslev et al. (1992) document the adequacy of the GARCH(1,1) specification. Li et al. (2002) provide an extensive review of recent theoretical results for univariate and multivariate time series models with conditional volatility errors. McAleer (2005) reviews a wide range of univariate and multivariate, conditional and stochastic, models of financial volatility. McAleer et al. (2007) discuss recent developments in modeling univariate asymmetric volatility, while McAleer et al. (2008) develop the regularity conditions and establish the asymptotic properties of a general model of timevarying conditional correlations. As shown in Figure 3, the log difference daily hog price data display time-varying volatility persistence, so it is natural to estimate alternative conditional volatility models.

Consider the stationary AR(1)-GARCH(1,1) model for daily hog prices in Taiwan (or their growth rates, as appropriate), $y_{t}$ :

$$
y_{t}=\phi_{1}+\phi_{2} y_{t-1}+\varepsilon_{t}, \quad\left|\phi_{2}\right|<1
$$

for $t=1, \ldots, n$, where the shocks (or movements in daily hog prices) are given by:

$$
\begin{aligned}
& \varepsilon_{t}=\eta_{t} \sqrt{h_{t}}, \quad \eta_{t} \sim \operatorname{iid}(0,1) \\
& h_{t}=\omega+\alpha \varepsilon_{t-1}^{2}+\beta h_{t-1},
\end{aligned}
$$


and $\omega>0, \alpha \geq 0, \beta \geq 0$ are sufficient conditions to ensure that the conditional variance $h_{t}>0$. The AR(1) model in equation (1) can easily be extended to univariate or multivariate $\operatorname{ARMA}(p, q)$ processes (for further details, see Ling and McAleer (2003a)). In equation (2), the ARCH (or $\alpha$ ) effect indicates the short run persistence of shocks, while the GARCH (or $\beta$ ) effect indicates the contribution of shocks to long run persistence (namely, $\alpha+\beta$ ). The stationary $\operatorname{AR}(1)-G A R C H(1,1)$ model can be modified to incorporate a non-stationary $\operatorname{ARMA}(p, q)$ conditional mean and a stationary $\operatorname{GARCH}(r, s)$ conditional variance, as in Ling and McAleer (2003b).

In equations (1) and (2), the parameters are typically estimated by the maximum likelihood method to obtain Quasi-Maximum Likelihood Estimators (QMLE) in the absence of normality of $\eta_{t}$, the conditional shocks (or standardized residuals). The conditional log-likelihood function is given as follows:

$$
\sum_{t=1}^{n} l_{t}=-\frac{1}{2} \sum_{t=1}^{n}\left(\log h_{t}+\frac{\varepsilon_{t}^{2}}{h_{t}}\right) \text {. }
$$

The QMLE is efficient only if $\eta_{t}$ is normal, in which case it is the MLE. When $\eta_{t}$ is not normal, adaptive estimation can be used to obtain efficient estimators, although this can be computationally intensive. Ling and McAleer (2003b) investigated the properties of adaptive estimators for univariate non-stationary ARMA models with $\operatorname{GARCH}(r, s)$ errors. The extension to multivariate processes is complicated.

As the GARCH process in equation (2) is a function of the unconditional shocks, the moments of $\varepsilon_{t}$ need to be investigated. Ling and McAleer (2003a) showed that the QMLE for $\operatorname{GARCH}(p, q)$ is consistent if the second moment of $\varepsilon_{t}$ is finite. For $\operatorname{GARCH}(p, q)$, Ling and $\mathrm{Li}(1997)$ demonstrated that the local QMLE is asymptotically normal if the fourth moment of $\varepsilon_{t}$ is finite, while Ling and McAleer (2003a) proved that the global QMLE is asymptotically normal if the sixth moment of $\varepsilon_{t}$ is finite. The well 
known necessary and sufficient condition for the existence of the second moment of $\varepsilon_{t}$ for $\operatorname{GARCH}(1,1)$ is $\alpha+\beta<1$.

As discussed in McAleer et al. (2007), Elie and Jeantheau (1995) and Jeantheau (1998) established that the log-moment condition was sufficient for consistency of the QMLE of a univariate GARCH $(p, q)$ process (see Lee and Hansen (1994) for the proof in the case of GARCH(1,1)), while Boussama (2000) showed that the log-moment condition was sufficient for asymptotic normality. Based on these theoretical developments, a sufficient condition for the QMLE of $\operatorname{GARCH}(1,1)$ to be consistent and asymptotically normal is given by the log-moment condition, namely

$$
E\left(\log \left(\alpha \eta_{t}^{2}+\beta\right)\right)<0
$$

The log-moment condition for the GARCH(1,1) model involves the expectation of a function of a random variable and unknown parameters. Although the sufficient moment conditions for consistency and asymptotic normality of the QMLE for the univariate $\operatorname{GARCH}(1,1)$ model are stronger than their log-moment counterparts, the second moment condition is more straightforward to check in practice. In practice, the log-moment condition in equation (3) would be estimated by the sample mean, with the parameters $\alpha$ and $\beta$, and the standardized residual, $\eta_{t}$, being replaced by their QMLE counterparts.

The effects of positive shocks (or upward movements in daily hog prices) on the conditional variance, $h_{t}$, are assumed to be the same as negative shocks (or downward movements in daily hog prices) of a similar magnitude in the symmetric GARCH model. In order to accommodate asymmetric behaviour, Glosten, Jagannathan and Runkle (1992) proposed the GJR model, for which GJR(1,1) is defined as follows:

$$
h_{t}=\omega+\left(\alpha+\gamma\left(\eta_{t-1}\right)\right) \varepsilon_{t-1}^{2}+\beta h_{t-1}
$$

where $\omega>0, \alpha \geq 0, \alpha+\gamma \geq 0, \beta \geq 0$ are sufficient conditions for $h_{t}>0$, and $I\left(\eta_{t}\right)$ is an indicator variable that is defined by: 


$$
I\left(\eta_{t}\right)= \begin{cases}1, & \varepsilon_{t}<0 \\ 0, & \varepsilon_{t} \geq 0\end{cases}
$$

as $\eta_{t}$ has the same sign as $\varepsilon_{t}$. The indicator variable differentiates between positive and negative shocks of equal magnitude, so that asymmetric effects in the data are captured by the coefficient $\gamma$. For financial data, it is typically expected that $\gamma \geq 0$ because negative shocks increase risk by increasing the debt to equity ratio, but this interpretation need not hold for hog price data in the absence of a similar interpretation in terms of risk. The asymmetric effect, $\gamma$, measures the contribution of shocks to both short run persistence, $\alpha+\frac{\gamma}{2}$, and to long run persistence, $\alpha+\beta+\frac{\gamma}{2}$.

Ling and McAleer (2002a) showed that the regularity condition for the existence of the second moment for GJR(1,1) under symmetry of $\eta_{t}$ is given by:

$$
\alpha+\beta+\frac{1}{2} \gamma<1
$$

while McAleer et al. (2007) showed that the weaker log-moment condition for GJR(1,1) was given by:

$$
E\left(\ln \left[\left(\alpha+\gamma I\left(\eta_{t}\right)\right) \eta_{t}^{2}+\beta\right]\right)<0
$$

which involves the expectation of a function of a random variable and unknown parameters.

An alternative model to capture asymmetric behaviour in the conditional variance is the Exponential GARCH (EGARCH(1,1)) model of Nelson (1991), namely:

$$
\log h_{t}=\omega+\alpha\left|\eta_{t-1}\right|+\gamma \eta_{t-1}+\beta \log h_{t-1}, \quad|\beta|<1
$$

where the parameters $\alpha, \beta$ and $\gamma$ have different interpretations from those in the GARCH(1,1) and GJR(1,1) models. 
As noted in McAleer et al. (2007), there are some important differences between EGARCH, on the one hand, and GARCH and GJR, on the other, as follows: (i) EGARCH is a model of the logarithm of the conditional variance, which implies that no restrictions on the parameters are required to ensure $h_{t}>0$; (ii) moment conditions are required for the GARCH and GJR models as they are dependent on lagged unconditional shocks, whereas EGARCH does not require moment conditions to be established as it depends on lagged conditional shocks (or standardized residuals); (iii) Shephard (1996) observed that $|\beta|<1$ is likely to be a sufficient condition for consistency of QMLE for EGARCH(1,1); (iv) as the standardized residuals appear in equation (7), $|\beta|<1$ would seem to be a sufficient condition for the existence of moments; and (v) in addition to being a sufficient condition for consistency, $|\beta|<1$ is also likely to be sufficient for asymptotic normality of the QMLE of $\operatorname{EGARCH}(1,1)$.

Furthermore, EGARCH captures asymmetries differently from GJR. The parameters $\alpha$ and $\gamma$ in EGARCH(1,1) represent the magnitude (or size) and sign effects of the standardized residuals, respectively, on the conditional variance, whereas $\alpha$ and $\alpha+\gamma$ represent the effects of positive and negative shocks, respectively, on the conditional variance in GJR(1,1). Asymmetric effects are captured by the coefficient $\gamma$, though in a different manner, in the EGARCH and GJR models. The EGARCH model is also capable of capturing leverage through the debt to equity ratio, whereby negative shocks increase volatility but positive shocks decrease volatility.

\section{Estimated Models}

It is well known that the estimates of volatility will depend on the adequacy of the specification of the conditional mean equation, which yields the standardized residuals. A related issue is the effect of ignoring structural change in the conditional mean of the estimates of the conditional variance (see, for example, Bai and Perron $(1998,2003)$ ). The effects of misspecifying the conditional mean on the estimates of the conditional volatility will be analyzed below. Both the asymptotic standard errors, as well as the 
robust standard errors of Bollerslev and Wooldridge (1992), are presented. In virtually all cases, the asymptotic standard errors are smaller than their robust counterparts.

The estimated conditional mean and conditional volatility models are given in Tables 3-6. As shown in the unit root tests, the levels and logarithms of daily hog prices are not stationary, but the log differences (or growth rates) are stationary. For this reason, only the growth rates and their associated volatility will be modelled for the full sample period, which is given in Table 3 , and for the three sub-samples, which are given in Tables 4-6.

These empirical results are supported by the estimates of the lagged dependent variables in the estimates of equation (1), with all the coefficients of the lagged dependent variable being less than one in each of the estimated three models for the growth rates of daily hog prices. This is consistent with the empirical finding that the log difference (or growth rate) is stationary.

As the second moment condition is less than unity in all cases, it follows that the weaker log-moment condition is less than zero in all cases (see Tables 3-6). Thus, the regularity conditions are satisfied, the QMLE are consistent and asymptotically normal, and inferences are valid. The EGARCH(1,1) model is based on the standardized residuals, so the regularity condition is satisfied if $|\beta|<1$, and hence the QMLE would seem to be consistent and asymptotically normal (see, for example, McAleer at al. (2007)).

As shown in Table 3, in the full sample estimation, the GARCH(1,1) estimates for the log different (or growth rate) of daily hog prices in Taiwan suggest that the short run persistence of shocks is 0.274 , while the long run persistence is 0.699 . As the second moment condition, $\alpha+\beta<1$, is satisfied, the log-moment condition is also satisfied. Therefore, the symmetric GARCH(1,1) estimates are statistically significant. 
If positive and negative shocks of a similar magnitude to daily hog prices in Taiwan are treated asymmetrically, this can be evaluated using the GJR(1,1) model. The asymmetry coefficient is found to be positive and significant for daily hog prices, namely 0.434 , which indicates that decreases in prices increase volatility. This is a consistent empirical outcome to that found in virtually all cases in empirical finance, where the negative shocks increase risk (or volatility). Moreover, the short run persistence of positive and negative shocks are estimated to be 0.104 and 0.538 , respectively, and the long run persistence of shocks is estimated to be 0.686 for the log difference in daily prices of hogs. As the second moment condition, $\alpha+\beta+\frac{1}{2} \gamma<1$, is satisfied, the logmoment condition is also satisfied, and the asymmetric $\operatorname{GJR}(1,1)$ estimates are statistically significant.

The interpretation of the EGARCH model is in terms of the logarithm of volatility. As shown in Table 3, each of the $\operatorname{EGARCH}(1,1)$ estimates is statistically significant. The coefficient of the lagged dependent variable, $\beta$, is estimated to be 0.668 and significant, which suggests that all moments exist, with the estimates likely to be consistent and asymptotically normal. Overall, the size effects of the standardized residuals, $\boldsymbol{\alpha}$, have a positive and significant impact on the conditional variances. However, the sign effect of the standardized residuals, $\gamma$, is negative and significant. Furthermore, the absolute vale of $\gamma$ is lower than for the corresponding $\alpha$ estimates, which suggests that the sign effects have smaller impacts than the size effects on the conditional variances. However, as the estimate of $\gamma$ is significant, asymmetry is evident, as in the case of the GJR model, but there is no leverage effect, whereby negative shocks increase volatility but positive shocks of a similar magnitude decrease volatility. These empirical results are similar to a wide range of financial stock market prices, so that the theory of finance is directly applicable to hog prices.

As given in Figures 1-3, the trends and volatilities in daily hog prices (as well as in their logarithms) seem to have experienced two noticeable structural changes during 
the sample period. As has already been mentioned, these changes would seem to have arisen from Taiwan's decision to join the World Trade Organization (WTO) in 2002, when the national government delegated efforts to protect domestic hog producers against lower imported hog prices. These actions may have altered the trends in the hog prices, as well as their associated volatility, in those periods. In order to investigate the effects of joining the WTO, alternative models of the growth rates and their associated volatility were estimated for three sub-samples before, during and after Taiwan joined the WTO, namely sub-sample 1 from 23 June 1999 to 27 December 2001, sub-sample 2 from 28 December 2001 to 6 August 2004, and sub-sample 3 from 7 August 2004 to 30 June 2007, respectively. The estimates for the three sub-sample periods are given separately in Tables 4-6.

Table 4 shows the statistical results for the $\operatorname{GARCH}(1,1)$, GJR(1,1) and EGARCH(1,1) models for sub-sample 1. Regarding the conditional mean estimates of the growth rate of daily hog prices, the estimates are predictable for the AR(1) conditional mean models associated with the GARCH $(1,1)$ and GJR $(1,1)$ volatility models, but not for the EGARCH $(1,1)$ model. This is slightly different from the estimates for the full sample period, in which the growth rates were predictable for all three models.

Regarding the conditional volatility estimates for sub-sample 1, it is clear from the estimates that volatility has time-varying persistence, with an estimated short run persistence of shocks of 0.284 and the estimated long run persistence of shocks of 0.873 for the symmetric GARCH $(1,1)$ model As the second moment condition, $\alpha+\beta<1$, is satisfied, the log-moment condition is also satisfied, and the symmetric GARCH(1,1) estimates are statistically significant.

For the GJR(1,1) model, both the second moment and log-moment conditions are satisfied. The asymptotic t-ratio for the $\gamma$ estimate is positive but not significant, suggesting that a negative shock will not affect risk (or volatility) any differently from a positive shock of equal magnitude. Furthermore, the short run persistence of positive shocks 0.275 , while the short run persistence of negative shocks is 0.299 . These results 
for GJR(1,1) suggest that both positive and negative shocks have significantly and similarly positive impacts on volatility.

The interpretation of the EGARCH model is in terms of the logarithm of volatility in sub-sample 1. As shown in Table 4, each of the EGARCH(1,1) estimates is statistically significant. Moreover, the coefficient of lagged log volatility, $\beta$, is estimated to be 0.807 and significant, which suggests that all moments exist, with the estimates likely to be consistent and asymptotically normal. Overall, the size effects of the standardized residuals, $\alpha$, have positive and significant impacts on the conditional variances, but the sign effect of the standardized residuals, $\gamma$, is negative but not significant. However, the absolute vale of $\gamma$, at 0.005 , is considerably lower than for the corresponding a estimate (0.490), which indicates that the sign effects have a much smaller, if any, impact than the size effects on the conditional variances. Overall, on the basis of the three conditional volatility models, there is a symmetric effect on volatility with regard to positive and negative shocks of equal magnitude.

Table 5 shows the statistical results for the $\operatorname{GARCH}(1,1)$, GJR(1,1) and EGARCH(1,1) models for sub-sample 2. With regard to the conditional mean estimates of the growth rate of daily hog prices, the estimates are significantly predictable for each of the three models. Moreover, the conditional means for the three models in sub-sample 2 are much stronger as compared with those in sub-sample 1 . Indeed, the magnitudes of the conditional means in sub-sample 2 are very similar to those of the full sample. These results would seem to suggest that sub-sample 2 may play a dominant role for predicting the growth rate of daily hog prices in Taiwan.

Regarding the conditional volatility estimates for sub-sample 2, the second moment condition, $\alpha+\beta<1$, is satisfied and hence the log-moment condition is also satisfied. Furthermore, the estimate for the short run persistence of shocks, $\alpha$, is 0.363 , which is larger than the corresponding estimate for sub-sample 1, whereas the long run 
persistence of 0.650 for the GARCH $(1,1)$ model is relatively smaller for sub-sample 2 than for sub-sample 1 . The $\beta$ estimate is significant and positive, but its magnitude is now considerably smaller. These results for $\operatorname{GARCH}(1,1)$ suggest that the short run persistence of shocks has a more significant impact on the conditional variance in the adjustment stage (sub-sample 2), whereas the impact of long run persistence has a more significant effect on the conditional variance in the planning stage (sub-sample 1). These outcomes are the opposite of those given in Table 4, in which there is a stronger long run persistence of shocks but a weaker short run persistence of shocks in sub-sample 1 .

With regard to the asymmetric effect, namely the $\gamma$ coefficient for the GJR(1,1) model in sub-sample 2, Table 5 shows that the estimate is positive and significant. Moreover, the magnitude of 0.342 is much larger than the corresponding estimate in subsample 1 at 0.024 . These results suggests that negative shocks have a much stronger impact on the conditional variance than do positive shocks of a similar magnitude, and that this effect is also stronger in sub-sample 2 than in sub-sample 1. Owing to the strong effect of negative shocks in sub-sample 2, the short run persistence of negative shocks on the conditional variance, at 0.480 , is much greater than for positive shocks of a similar magnitude, at 0.138. However, the short run persistence of positive shocks on the conditional variance is not as strong for sub-sample 2 as compared with the corresponding effect for sub-sample 1.

Furthermore, the long run persistence of shocks, at 0.662, in sub-sample 2 is much lower than that in sub-sample 1 , at 0.868. Moreover, in comparison with subsample 1, the magnitude of the long run persistence of shocks is similar to that for the full sample period. These results suggest that the data for sub-sample 2 can play a dominant role in evaluating the effect of the long run persistence of shocks. Moreover, both the second moment and log-moment condition are satisfied for the GJR(1,1) model.

The interpretation of the EGARCH model is in terms of the logarithm of volatility for sub-sample 2. As shown in Table 5, each of the $\operatorname{EGARCH}(1,1)$ estimates is 
statistically significant. Moreover, the coefficient of the lagged dependent variable, $\beta$, is estimated to be 0.727 and significant, which suggests that all moments exist. Furthermore, the size effects of the standardized residuals, $\alpha$, have positive and significant impacts on the conditional variances, and the sign effect of the standardized residuals, $\gamma$, on the conditional variances is negative and significant. Moreover, in comparison with sub-sample 1 , the impact of $\gamma$ is larger in sub-sample 2, which suggests that negative shocks have a more significant impact in this period on the conditional variance. Overall, on the basis of the three conditional volatility models, there is an asymmetric effect on volatility with regard to positive and negative shocks of equal magnitude. However, there is no leverage effect, whereby negative shocks increase volatility but positive shocks of a similar magnitude decrease volatility.

Table 6 shows the statistical results for the $\operatorname{GARCH}(1,1)$, $\operatorname{GJR}(1,1)$ and EGARCH(1,1) models for sub-sample 3. In a comparative perspective, it is clear that the conditional means, as well as the conditional volatility for the growth rates of daily hog prices in the sub-sample 3 , are vastly different from the corresponding estimates for subsamples 1 and 2. The conditional mean estimates are only predictable for the GARCH $(1,1)$ model, but the effect of the conditional mean model for the GARCH(1,1) model is even lower than the estimates for sub-sample 3.

Regarding the conditional volatility for sub-sample 3, the estimates make it clear that volatility is persistent, with a relatively small value of $\alpha$, at 0.079 , and a relatively large value of $\beta$, at 0.602 , which are the estimates of the contributions of the shocks to long run persistence in the GARCH $(1,1)$ model. However, in comparison with the magnitude of the coefficient of short run persistence of shocks among the three subsamples, sub-sample 3 shows the weakest impact of short run persistence on the conditional variance. As the second moment condition, $\alpha+\beta<1$, is satisfied, the logmoment condition is also satisfied, and the symmetric $\operatorname{GARCH}(1,1)$ estimates are statistically significant. 
For the GJR(1,1) model, both the second moment and log-moment conditions are both satisfied. The asymptotic t-ratio for the $\gamma$ estimate in Table 6 is highly significant, suggesting that negative shocks increase risk (or volatility) significantly in sub-sample 3 as compared with positive shocks of a similar magnitude. Moreover, the magnitude of the asymmetric effect, $\gamma$, at 0.473 , is now much larger and more prominent than was observed in the other sub-samples. These results imply that negative shocks still have a strong impact on the conditional variance in the settlement period. The $\beta$ estimate is significantly positive, while the estimate of $\alpha$ is now negative, though insignificant. Overall, the short run persistence of negative shocks on the conditional variance is 0.452 and the long run persistence of shocks is 0.563 , which indicates the weakest impact on the conditional variance among the various sub-samples. Furthermore, the second moment and log-moment conditions are satisfied for the GJR(1,1) model.

The interpretation of the EGARCH model is in terms of the logarithm of volatility for sub-sample 3. As shown in Table 6, each of the $\operatorname{EGARCH}(1,1)$ estimates is statistically significant, and the coefficient of the lagged dependent variable, $\beta$, is estimated to be 0.452 and significant, which suggests that all moments exist. Again, the size effects of the standardized residuals, $\alpha$, have positive and significant impacts on the conditional variances, while the sign effect of the standardized residuals, $\gamma$, on the conditional variances is now negative and significant. It is worth emphasizing that the conditions for leverage in the $\operatorname{EGARCH}(1,1)$ model are satisfied, which suggests that negative shocks increase volatility but positive shocks of a similar magnitude decrease volatility in the settlement period, namely sub-sample 3. Consequently, the settlement stage of WTO entry has altered hog prices to behave just like some financial stock market prices.

In a comparison of the estimates for the three sub-samples, it may be concluded that the long run persistence of shocks in the planning period (that is, sub-sample 1) 
suggests a more significant impact on the conditional variance than in the other two subsamples. In addition, the short run persistence of shocks in the settlement period (that is, sub-sample 3) suggests the weakest impact on the conditional variance among the three sub-samples. Overall, the asymmetric effect is found to be significant for the GJR $(1,1)$ model in two of the three sub-samples, while the effect of negative shocks has tended to increase over the full sample period. However, in the asymmetric EGARCH(1,1) model, a leverage effect is observed only in the settlement period (that is, sub-sample 3), whereas it is not significant in sub-period 1 and is significant, but does not suggest the existence of leverage effects, in sub-sample 2. In summary, the adjustment period (that is, subsample 2) implies a dominant contributing role for estimating the impact of the short run and long run persistence of shocks for the full sample period.

In general, the QMLE for the GARCH(1,1), GJR(1,1) and EGARCH(1,1) models for the log differences (or growth rate) in daily hog prices in Taiwan are statistically adequate and have sensible interpretations. For the full sample period, in which any structural changes are ignored, there is asymmetry in volatility for the $G \operatorname{JR}(1,1)$ and EGARCH(1,1) models, but there is no presence of leverage effects, whereby negative shocks increase volatility but positive shocks of a similar magnitude decrease volatility. The three sub-samples exhibit different types of symmetry or asymmetry, with the period prior to joining the WTO showing symmetry, the period of joining displaying asymmetry but not leverage, and the period after joining indicating leverage. This enables an empirical analysis of the effects on the prices of the hog production industry of joining the WTO by Taiwan, whereby hog prices behave very much like financial commodity prices.

\section{Concluding Remarks}

The paper presented a novel application of financial volatility models to agricultural finance, and should be relevant for the analysis of other agricultural commodities in different countries. Specifically, the paper modelled the growth rates and volatility (or variability in the growth rate) in daily hog prices in Taiwan from 23 March 
1999 to 30 June 2007, which enables an analysis of the effects of joining the WTO. The empirical results show that the time series of daily hog prices and their logarithms were non-stationary, but that their log differences (or growth rates) were stationary. In addition, the estimated symmetric and asymmetric conditional volatility models, specifically the widely used GARCH, GJR and EGARCH models, for the growth rates all fit the data extremely well.

The estimated models were able to account for the volatility persistence that was observed in three sub-samples for the log difference (or growth rate) in daily hog prices, namely 23 June 1999 to 27 December 2001 (sub-sample 1), 28 December 2001 to 6 August 2004 (sub-sample 2), and 7 August 2004 to 30 June 2007 (sub-sample 3). The empirical second moment and log-moment conditions also supported the statistical adequacy of the estimated symmetric and asymmetric conditional volatility models.

These empirical results have significant implications for risk management and policy considerations in the agricultural industry in Taiwan, especially when significant structural changes such as joining the WTO are concerned. The three sub-samples relating to the period before, during and after joining the WTO displayed significantly different volatility persistence, namely symmetry, asymmetry but not leverage, and leverage, respectively, whereby negative shocks increase volatility but positive shocks of a similar magnitude decrease volatility. As hog prices behave very similarly to financial stock market prices, the theory of finance and optimal risk management can be applied directly to the analysis of agricultural commodity prices. 


\section{References}

Bai, J. and P. Perron (1998), Estimating and testing linear models with multiple structural changes, Econometrica, 66, 47-78.

Bai, J. and P. Perron (2003), Computation and analysis of multiple structural change models, Journal of Applied Econometrics, 18, 1-22.

Bollerslev, T. (1986), Generalised autoregressive conditional heteroscedasticity, Journal of Econometrics, 31, 307-327.

Bollerslev, T., R.Y. Chou and K.F. Kroner (1992), ARCH modeling in finance - a review of the theory and empirical evidence, Journal of Econometrics, 52, 5-59.

Bollerslev, T. and J. Wooldridge (1992), Quasi maximum likelihood estimation and inference in dynamic models with time varying variances, Econometric Reviews, $11,143-172$.

Boussama, F. (2000), Asymptotic normality for the quasi-maximum likelihood estimator of a GARCH model, Comptes Rendus de l'Academie des Sciences, Serie I, 331, 8184 (in French).

Chang, S.M (1999), An econometric analysis of changes in hog price and major pork price variability in Taiwan - an application of ARCH regression model, Journal of Agricultural Economics (Taiwan) (semiannual publication), 65, 117-140.

Dickey, D.A. and W.A. Fuller (1979), Distribution of the estimators for autoregressive time series with a unit root, Journal of the American Statistical Association, 74, 427-431.

Dickey, D.A. and W.A. Fuller (1981), Likelihood ratio statistics for autoregressive time series with a unit root, Econometrica, 49, 1057-1072.

Egelkraut, T.M., P. Garcia, and B.J. Sherrick (2007), The term structure of implied forward volatility: Recovery and informational content in the corn options market, American Journal of Agricultural Economics, 89, 1-11.

Elie, L. and T. Jeantheau (1995), Consistency in heteroskedastic models, Comptes Rendus de l'Académie des Sciences, Série I, 320, 1255-1258 (in French).

Elliott, G., T.J. Rothenberg and J.H. Stock (1996), Efficient tests for an autoregressive unit root, Econometrica, 64, 813-836. 
Engle, R.F. (1982), Autoregressive conditional heteroscedasticity with estimates of the variance of United Kingdom inflation, Econometrica, 50, 987-1007.

Glosten, L., R. Jagannathan and D. Runkle (1992), On the relation between the expected value and volatility of nominal excess return on stocks, Journal of Finance, 46, 1779-1801.

Jeantheau, T. (1998), Strong consistency of estimators for multivariate ARCH models, Econometric Theory, 14, 70-86.

Jin, H.J. and D.L. Frechette (2004), Fractional integration in agricultural futures price volatilities, American Journal of Agricultural Economics, 86, 432-443.

Koekebakker, S. and G. Lien (2004), Volatility and price jumps in agricultural futures prices - evidence from wheat options, American Journal of Agricultural Economics, 86, 1018-1031.

Langley, S.V., M.G. Giugale, W.H. Meyers and C. Hallahan (2000), International financial volatility and agricultural commodity trade: A primer, American Journal of Agricultural Economics, 82, 695-700.

Lence, S.H., and D.J. Hayes (2002), U.S. farm policy and the volatility of commodity prices and farm revenues, American Journal of Agricultural Economics, 84, 335351.

Lee, S.W. and B.E. Hansen (1994), Asymptotic theory for the GARCH(1,1) quasimaximum likelihood estimator, Econometric Theory, 10, 29-52.

Li, W.K., S. Ling and M. McAleer (2002), Recent theoretical results for time series models with GARCH errors, Journal of Economic Surveys, 16, 245-269. Reprinted in M. McAleer and L. Oxley (eds.), Contributions to Financial Econometrics: Theoretical and Practical Issues, Blackwell, Oxford, 2002, pp. 9-33.

Lien, D. and D.A. Hennessy (2007), Cash flow effects of the Saskatchewan short-term hog loan program, Canada Journal of Agricultural Economics, 55, 83-96.

Ling, S. and W.K. Li (1997), On fractionally integrated autoregressive moving-average models with conditional heteroskedasticity, Journal of the American Statistical Association, 92, 1184-1194.

Ling, S. and M. McAleer (2002a), Stationarity and the existence of moments of a family of GARCH processes, Journal of Econometrics, 106, 109-117. 
Ling, S. and M. McAleer (2002b), Necessary and sufficient moment conditions for the GARCH(r,s) and asymmetric power GARCH(r,s) models, Econometric Theory, 18, 722-729.

Ling, S. and M. McAleer, (2003a), Asymptotic theory for a vector ARMA-GARCH model, Econometric Theory, 19, 278-308.

Ling, S. and M. McAleer (2003b), On adaptive estimation in nonstationary ARMA models with GARCH errors, Annals of Statistics, 31, 642-674.

McAleer, M. (2005), Automated inference and learning in modeling financial volatility, Econometric Theory, 21, 232-261.

McAleer, M. (2008), The Ten Commandments for optimizing value-at-risk, to appear in Journal of Economic Surveys.

McAleer, M., F. Chan and D. Marinova (2007), An econometric analysis of asymmetric volatility: Theory and application to patents, Journal of Econometrics, 139, 259284.

McAleer, M., F. Chan, S. Hoti and O. Lieberman (2008), Generalized autoregressive conditional correlation, to appear in Econometric Theory.

Nelson, D.B. (1991), Conditional heteroscedasticity in asset returns: a new approach, Econometrica, 59, 347-370.

Ng, S. and P. Perron (2001), Lag length selection and the construction of unit root tests with good size and power, Econometrica, 69, 1519-1554.

Perron, P. and S. Ng (1996), Useful modifications to some unit root tests with dependent errors and their local asymptotic properties, Review of Economic Studies, 63, 435463.

Phillips, P.C.B. and P. Perron (1988), Testing for a unit root in time series regression, Biometrika, 75, 335-346.

Schroeter, J. and A. Azzam (1991), Marketing margins, market power, and price uncertainty, American Journal of Agricultural Economics, 73, 990-999.

Shephard, N. (1996), Statistical aspects of ARCH and stochastic volatility, in O.E. Barndorff-Nielsen, D.R. Cox and D.V. Hinkley (eds.), Statistical Models in Econometrics, Finance and Other Fields, Chapman \& Hall, London, pp. 1-67. 
Shively, G.E. (2001), Price thresholds, price volatility, and the private costs of investment in a developing country grain market, Economic Modelling, 18, 399-414.

Yang, S.-R. and B.W. Brorsen (1992), Nonlinear dynamics of daily cash prices, American Journal of Agricultural Economics, 74, 706-715. 
Figure 1. Hog Price (New Taiwan Dollars per kilogram) (Y)

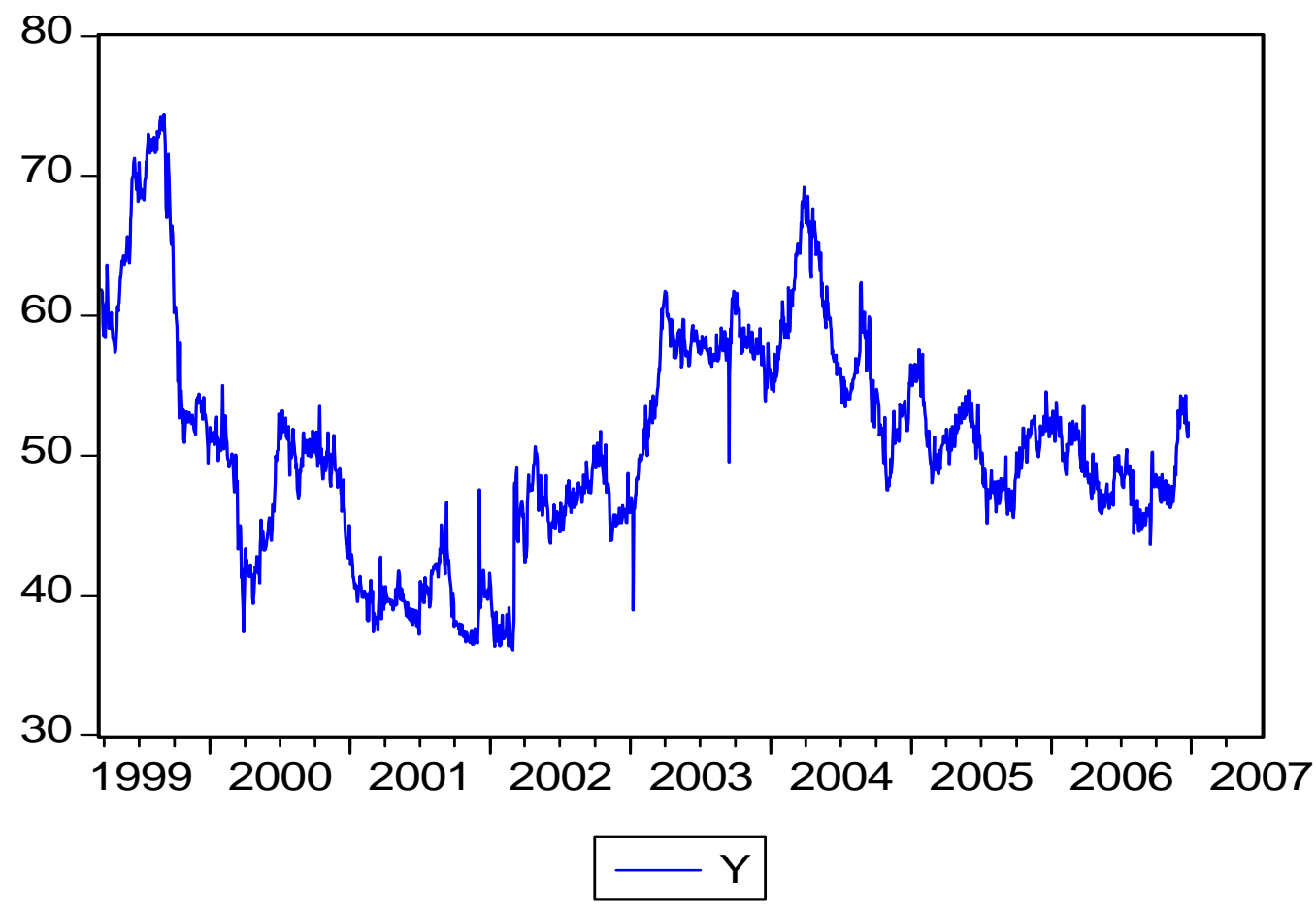


Figure 2. Logarithm of Hog Price (New Taiwan Dollars per kilogram) (LY)

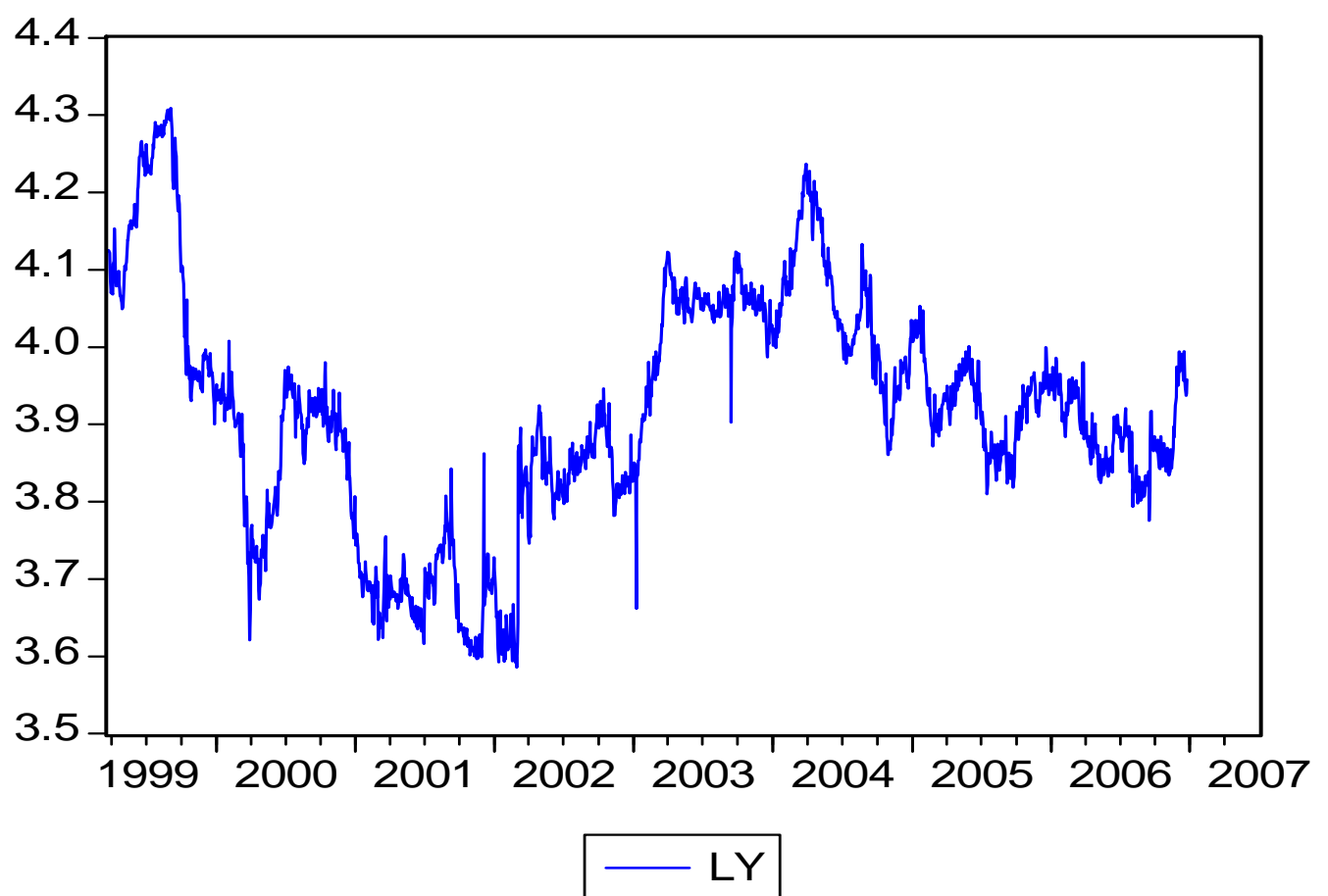


Figure 3. Log Difference of Hog Price (New Taiwan Dollars per kilogram) (DLY)

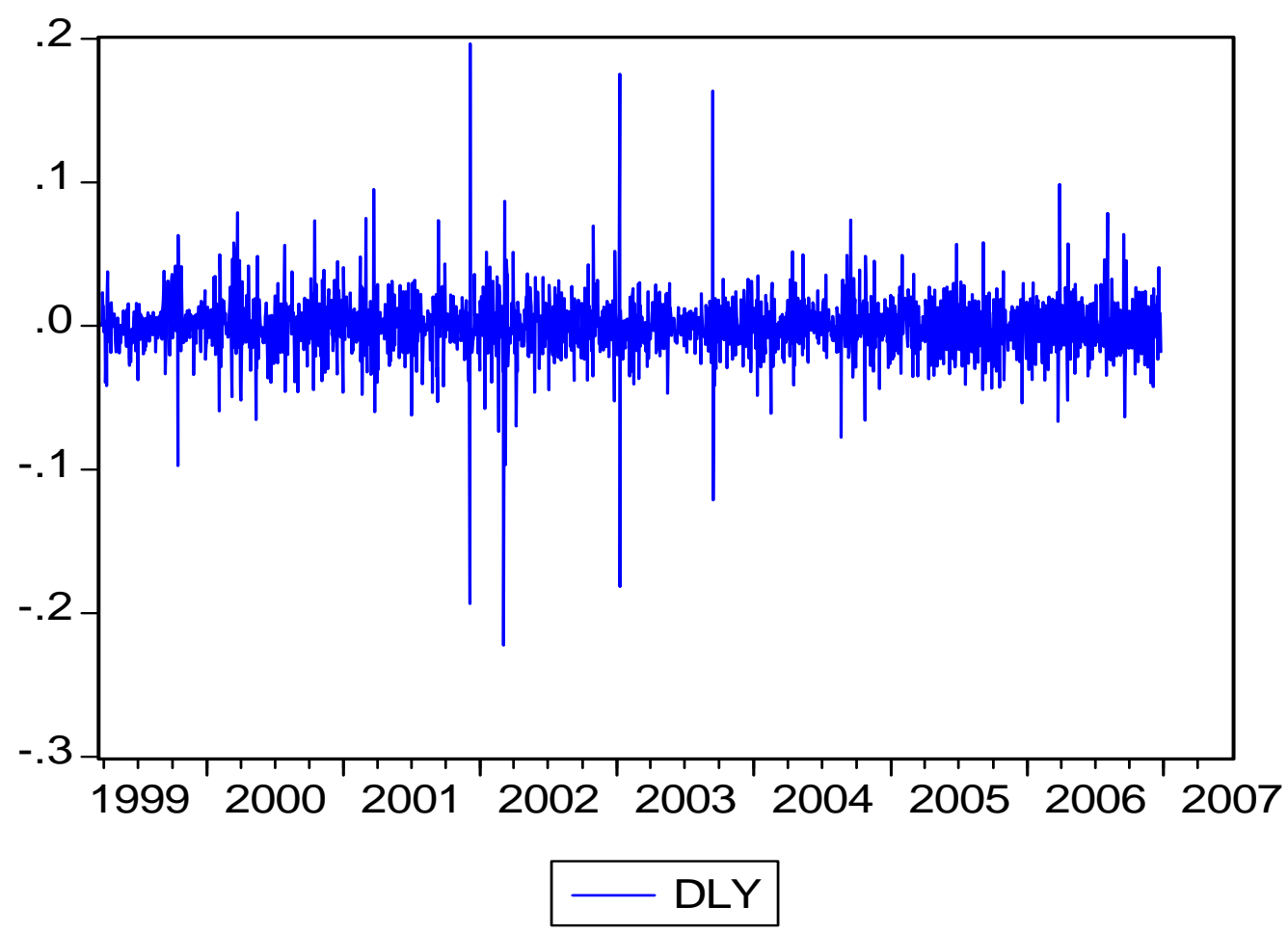


Table 1. Chow Breakpoint Test

\begin{tabular}{ccc}
\hline Test & Statistic & p-value \\
\hline F & $3.07^{* *}$ & 0.015 \\
Likelihood ratio & $12.30^{* *}$ & 0.015 \\
\hline
\end{tabular}

Note:

** Denotes the null hypothesis of no structural change across the three regimes, namely 1999/3/23-2001/12/27, 2001/12/28-2004/8/6 and 2004/8/7-2007/6/30, is rejected at the $5 \%$ level.

Table 2a. Unit Root Tests - Full Sample from 1999/3/23 - 2007/6/30

\begin{tabular}{ccccc}
\hline Variables & $\mathrm{MADF}^{\mathrm{GLS}}$ & $\mathrm{MPP}^{\mathrm{GLS}}$ & $\mathrm{MADF}$ & $\mathrm{MPP}^{\mathrm{GLS}}$ \\
& $\mathrm{Z}=\{1\}$ & $\mathrm{Z}=\{1\}$ & $\mathrm{Z}=\{1, \mathrm{t}\}$ & $\mathrm{Z}=\{1, \mathrm{t}\}$ \\
\cline { 2 - 5 } $\mathrm{Y}$ & -1.05 & -1.56 & -2.44 & -5.04 \\
$\mathrm{LY}$ & -1.13 & -2.79 & $-3.52^{* * *}$ & -6.37 \\
$\mathrm{DLY}$ & $-28.16^{* * *}$ & $-5682.73^{* * *}$ & $-31.34^{* * *}$ & $-1893.77^{* * *}$ \\
\hline Notes: & $* * *$ & denotes the null hypothesis of a unit root is rejected at the $1 \%$ level. &
\end{tabular}

Table 2b. Unit Root Tests - Sub-sample 1 from 1999/3/23 - 2001/12/27

\begin{tabular}{ccccc}
\hline Variables & $\mathrm{MADF}^{\mathrm{GLS}} ;$ & $\mathrm{MPP}^{\mathrm{GLS}}$ & $\mathrm{MADF}^{\mathrm{GLS}}$ & $\mathrm{MPP}^{\mathrm{GLS}}$ \\
& $\mathrm{Z}=\{1\}$ & $\mathrm{Z}=\{1\}$ & $\mathrm{Z}=\{1, t\}$ & $\mathrm{Z}=\{1, \mathrm{t}\}$ \\
\cline { 2 - 5 } $\mathrm{Y}$ & -0.03 & -0.05 & -2.21 & -9.67 \\
$\mathrm{LY}$ & -0.03 & -0.04 & -2.54 & -12.66 \\
$\mathrm{DLY}$ & $-21.32^{* * *}$ & $-434.03^{* * *}$ & $-21.28^{* * *}$ & $-432.83^{* * *}$ \\
\hline Notes: & $* * *$ & denotes the null hypothesis of a unit root is rejected at the 1\% level.
\end{tabular}

Table 2c. Unit Root Tests - Sub-sample 2 from 2001/12/28 - 2004/8/6

\begin{tabular}{ccccc}
\hline Variables & $\mathrm{MADF}^{\mathrm{GLS}}$ & $\mathrm{MPP}^{\mathrm{GLS}}$ & $\mathrm{MADF}$ & $\mathrm{MPP}^{\mathrm{GLS}}$ \\
& $\mathrm{Z}=\{1\}$ & $\mathrm{Z}=\{1\}$ & $\mathrm{Z}=\{1, t\}$ & $\mathrm{Z}=\{1, \mathrm{t}\}$ \\
\cline { 2 - 5 } $\mathrm{Y}$ & 1.02 & -1.34 & $-2.92^{* *}$ & $-13.27^{*}$ \\
$\mathrm{LY}$ & 0.73 & 0.99 & $-2.95^{* *}$ & -12.36 \\
$\mathrm{DLY}$ & $-1.98^{* *}$ & -5.08 & $-3.84^{* * *}$ & -11.77 \\
\hline Notes: & $* * *$ & denotes the null hypothesis of a unit root is rejected at the $1 \%$ level.
\end{tabular}

Table 2d. Unit Root Tests - Sub-sample 3 from 2004/8/7 - 2007/6/30

\begin{tabular}{ccccc}
\hline Variables & $\mathrm{MADF}^{\mathrm{GLS}}$ & $\mathrm{MPP}^{\mathrm{GLS}}$ & $\mathrm{MADF}^{\mathrm{GLS}}$ & $\mathrm{MPP}^{\mathrm{GLS}}$ \\
& $\mathrm{Z}=\{1\}$ & $\mathrm{Z}=\{1\}$ & $\mathrm{Z}=\{1, \mathrm{t}\}$ & $\mathrm{Z}=\{1, \mathrm{t}\}$ \\
\cline { 2 - 5 } $\mathrm{Y}$ & -0.03 & 0.04 & -0.88 & -1.55 \\
$\mathrm{LY}$ & -0.17 & -0.22 & -1.10 & -3.24 \\
DLY & $-5.16^{* * *}$ & $-18.34^{* * *}$ & $-8.87^{* * *}$ & $-67.58^{* * *}$ \\
\hline
\end{tabular}

Notes: $* * *$ denotes the null hypothesis of a unit root is rejected at the $1 \%$ level. 
Table 3. Conditional Mean and Volatility Models for Log Difference in Prices for Full Sample,

1999/3/23 - 2007/6/30

\begin{tabular}{|c|c|c|c|}
\hline \multirow{2}{*}{ Parameters } & \multicolumn{3}{|c|}{ Dependent variable: DLY } \\
\hline & GARCH & GJR & EGARCH \\
\hline$\phi_{1}$ & $\begin{array}{c}0.0004 \\
(0.0004) \\
{[0.0005]}\end{array}$ & $\begin{array}{c}-0.0004 \\
(0.0004) \\
{[0.0004]}\end{array}$ & $\begin{array}{c}-0.0005 \\
(0.0004) \\
{[0.0004]}\end{array}$ \\
\hline$\phi_{2}$ & $\begin{array}{c}-0.143^{\star \star \star} \\
(0.028) \\
{[0.039]} \\
\end{array}$ & $\begin{array}{c}-0.103^{* \star \star} \\
(0.026) \\
{[0.039]} \\
\end{array}$ & $\begin{array}{c}-0.101^{\star \star \star} \\
(0.025) \\
{[0.036]}\end{array}$ \\
\hline$\omega$ & $\begin{array}{l}0.0001^{\star \star \star} \\
(0.00001) \\
{[0.00003]}\end{array}$ & $\begin{array}{l}0.0002^{\star \star \star} \\
(0.00001) \\
{[0.00003]}\end{array}$ & $\begin{array}{c}-2.907^{\star \star \star} \\
(0.258) \\
{[0.628]}\end{array}$ \\
\hline GARCH/GJR $\alpha$ & $\begin{array}{c}0.274^{\star \star \star} \\
(0.016) \\
{[0.106]}\end{array}$ & $\begin{array}{c}0.104^{\star \star \star} \\
(0.019) \\
{[0.068]}\end{array}$ & -- \\
\hline GARCH/GJR $\beta$ & $\begin{array}{c}0.425^{\star \star \star} \\
(0.034) \\
{[0.102]}\end{array}$ & $\begin{array}{c}0.365^{\star \star *} \\
(0.030) \\
{[0.101]}\end{array}$ & -- \\
\hline GJR $\gamma$ & -- & $\begin{array}{c}0.434^{\star \star \star} \\
(0.038) \\
{[0.200]^{\star \star}}\end{array}$ & -- \\
\hline EGARCH $\alpha$ & -- & -- & $\begin{array}{c}0.423^{\star * \star} \\
(0.023) \\
(0.077)\end{array}$ \\
\hline EGARCH $\gamma$ & -- & -- & $\begin{array}{c}-0.148^{\star \star \star} \\
(0.016) \\
{[0.070]^{\star \star}}\end{array}$ \\
\hline EGARCH $\beta$ & -- & -- & $\begin{array}{c}0.668^{\star \star *} \\
(0.032) \\
{[0.078]} \\
\end{array}$ \\
\hline \multicolumn{4}{|l|}{ Diagnostics } \\
\hline $\begin{array}{l}\text { Second moment } \\
\text { Log-moment }\end{array}$ & $\begin{array}{r}0.699 \\
-0.231\end{array}$ & $\begin{array}{c}0.686 \\
-0.264\end{array}$ & $\begin{array}{l}-- \\
--\end{array}$ \\
\hline
\end{tabular}

Notes:

DLY is Log Difference in Hog Price (New Taiwan Dollars per kilogram)

Numbers in parentheses are asymptotic standard errors, while numbers in brackets are the Bollerslev and Wooldridge robust standard errors.

** and *** denote significance at the $5 \%$ and $1 \%$ level, respectively. 
Table 4. Conditional Mean and Volatility Models for Log Difference in Prices for Sub-sample 1, 1999/3/23-2001/12/27

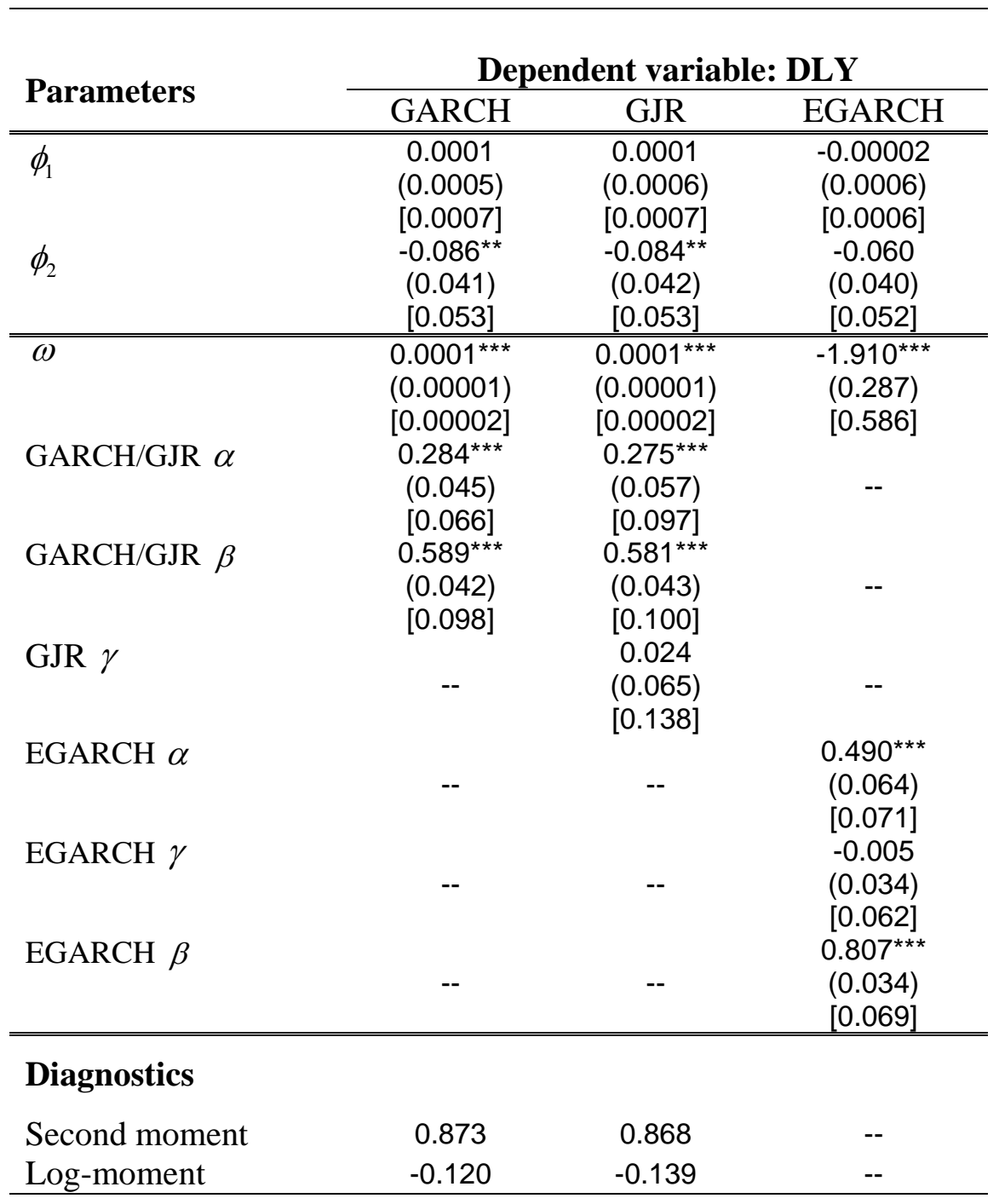

Notes:

DLY is Log Difference in Hog Price (New Taiwan Dollars per kilogram) Numbers in parentheses are asymptotic standard errors, while numbers in brackets are the Bollerslev and Wooldridge robust standard errors.

** and ${ }^{* * *}$ denote significance at the $5 \%$ and $1 \%$ levels, respectively. 
Table 5. Conditional Mean and Volatility Models for Log Difference in Prices for Sub-sample 2

2001/12/28 - 2004/8/6

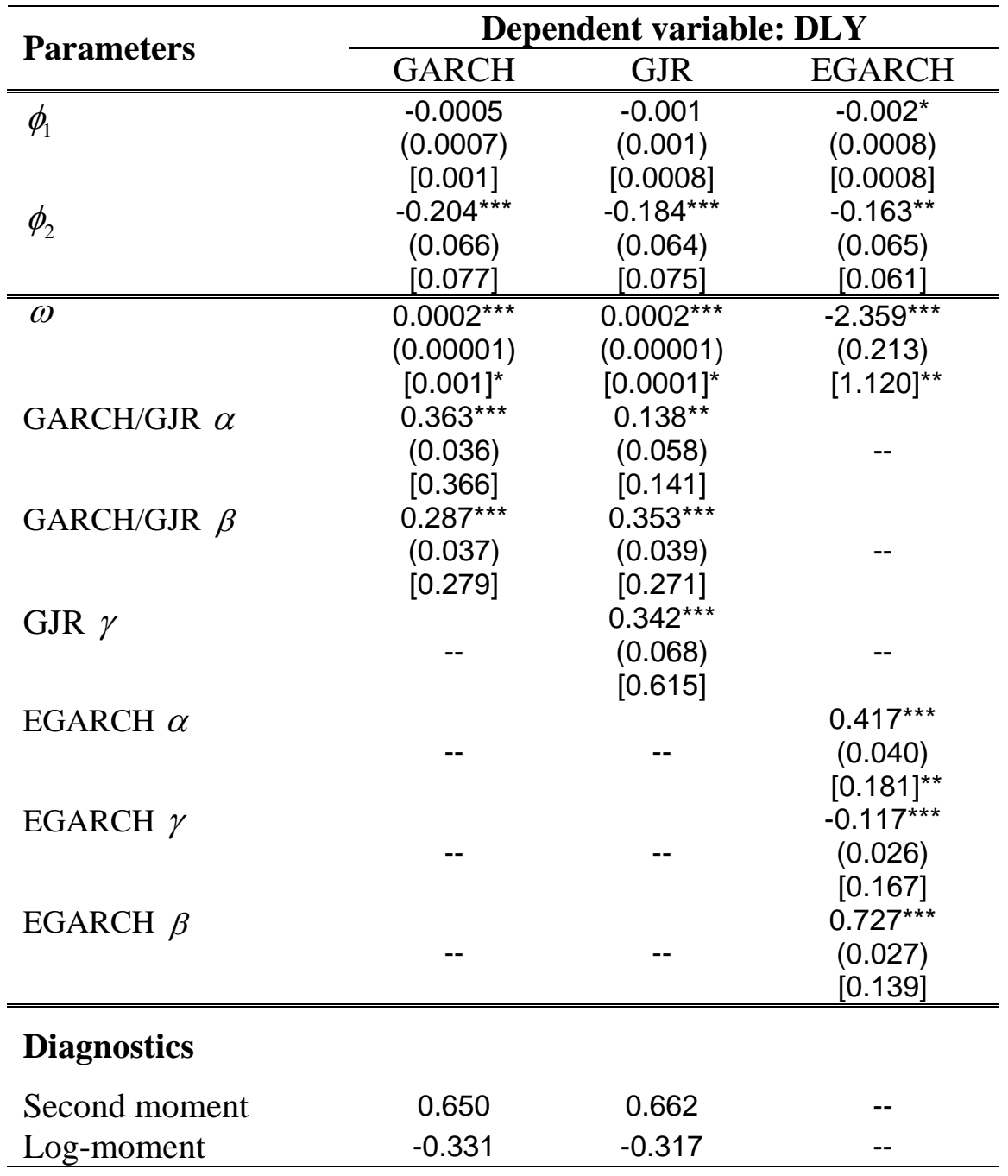

Notes:

DLY is Log Difference in Hog Price (New Taiwan Dollars per kilogram)

Numbers in parentheses are asymptotic standard errors, while numbers in brackets are the Bollerslev and Wooldridge robust standard errors.

$*$, ** and $* * *$ denote significance at the $10 \%, 5 \%$ and $1 \%$ levels, respectively. 
Table 6. Conditional Mean and Volatility Models for Log

Difference in Prices for Sub-sample 3

2004/8/7 - 2007/6/30

\begin{tabular}{|c|c|c|c|}
\hline \multirow{2}{*}{ Parameters } & \multicolumn{3}{|c|}{ Dependent variable: DLY } \\
\hline & GARCH & GJR & EGARCH \\
\hline \multirow{3}{*}{$\overline{\phi_{1}}$} & 0.0005 & -0.005 & -0.0004 \\
\hline & $(0.0007)$ & $(0.0007)$ & $(0.0007)$ \\
\hline & {$[0.0007]$} & {$[0.0007]$} & {$[0.0007]$} \\
\hline \multirow{3}{*}{$\phi_{2}$} & $-0.095^{\star \star}$ & -0.053 & -0.057 \\
\hline & $(0.043)$ & $(0.038)$ & $(0.035)$ \\
\hline & [0.043] & [0.041] & [0.041] \\
\hline \multirow[t]{3}{*}{$\overline{\omega \omega}$} & $0.0001^{\star \star \star}$ & $0.0002^{\star \star \star}$ & $-4.522^{\star \star \star \star}$ \\
\hline & $(0.00004)$ & $(0.00001)$ & $(0.459)$ \\
\hline & {$[0.0001]$} & {$[0.00009]^{*}$} & [3.036] \\
\hline \multirow[t]{3}{*}{ GARCH/GJR $\alpha$} & $0.079 * \star \star$ & -0.021 & \\
\hline & $(0.031)$ & (0.019) & -- \\
\hline & {$[0.041]^{\star}$} & [0.023] & \\
\hline \multirow[t]{3}{*}{ GARCH/GJR $\beta$} & $0.602^{\star \star \star}$ & $0.347^{\star * \star}$ & \\
\hline & $(0.130)$ & $(0.055)$ & -- \\
\hline & {$[0.294]^{\star *}$} & {$[0.290]$} & \\
\hline \multirow{2}{*}{ GJR $\gamma$} & & $0.473^{\star \star \star}$ & \\
\hline & -- & $\begin{array}{l}(0.117) \\
{[0.108]}\end{array}$ & -- \\
\hline \multirow{2}{*}{ EGARCH $\alpha$} & & & $0.158^{\star \star \star}$ \\
\hline & -- & -- & $\begin{array}{l}(0.054) \\
{[0.133]}\end{array}$ \\
\hline \multirow[t]{2}{*}{ EGARCH $\gamma$} & & & $-0.305^{\star \star \star}$ \\
\hline & -- & -- & $\begin{array}{l}(0.044) \\
{[0.069]}\end{array}$ \\
\hline \multirow[t]{2}{*}{ EGARCH $\beta$} & & & $0.452^{\star \star \star}$ \\
\hline & -- & -- & $\begin{array}{l}(0.058) \\
{[0.367]}\end{array}$ \\
\hline \multicolumn{4}{|l|}{ Diagnostics } \\
\hline Second moment & 0.681 & 0.563 & -- \\
\hline Log-moment & -0.180 & -0.376 & -- \\
\hline
\end{tabular}

Notes:

DLY is Log Difference in Hog Price (New Taiwan Dollars per kilogram)

Numbers in parentheses are asymptotic standard errors, while numbers in brackets are the Bollerslev and Wooldridge robust standard errors.

$* *$ and $* * *$ denote significance at the $5 \%$ and $1 \%$ levels, respectively. 